\title{
The Mediating Effect of Quality and Prestige on the Relationship between Brand Globalness and Purchase Likelihood of HTC Mobile Phone
}

\author{
Massoud Moslehpour ${ }^{1}$, Van Kien Pham ${ }^{1} \&$ Selman Yumnu ${ }^{2}$ \\ ${ }^{1}$ Department of Business Administration, Asia University, Taiwan \\ ${ }^{2}$ Department of Tourism Sakarya Universitesi Hendek, Turkey \\ Correspondence: Van Kien Pham, Department of Business Administration, Asia University, 500 Lioufeng Road \\ Wufeng Dist. Taichung City, 41354, Taiwan. Tel: 8864-2332-2345. E-mail: phamtrungkien981987@yahoo.com
}

Received: November 5, 2013

Accepted: December 1, 2013

Online Published: December 23, 2013

doi: 10.5539/ibr.v7n1p94

URL: http://dx.doi.org/10.5539/ibr.v7n1p94

\begin{abstract}
Perceived brand quality (PBQ) and perceived brand prestige (PBP) have been considered very important mechanisms to predict the direct as well as indirect relationship between perceived brand globalness (PBG) and consumer purchase likelihood (CPL) in many studies. However, almost all studies focused on direct influence of PBQ and PBP on CPL, neglecting the mediating role of them. This study, therefore, aims at filling this research gap by investigating the mediating effects of $\mathrm{PBQ}$ and PBP on the relationship between the PBG and CPL in the mobile industry applied to the HTC Company. In doing so, this study used the structural equation modeling (SEM) approach to analyze a total sample of 439 college student consumers in central Taiwan. Results indicated that PBG and BPQ have positive effects on CPL while PBP did not. These findings are different from the literature that both PBQ and BBP showed significant influences on CPL. In other words, when it comes to HTC mobile phone, only PBQ could be considered as a mediating variable through which PBG indirectly affects CPL. Generally, this study opens the doors to new empirical studies in the mobile phone industry whereby readers and practitioners would understand the importance of mediator role in consumer purchase intention.
\end{abstract}

Keywords: perceived brand globalness, perceived brand quality, perceived brand prestige, consumer purchasing likelihood, Structural Equation Modeling (SEM), smart phone industry, HTC

\section{Introduction}

Global marketing has had a huge impact on both local and global brands. Given the fact that strong local brands have an advantage of developing close contact with domestic customers, it can be challenging for foreign brands to convince consumers to use their products and brands. At the same time, local brands are constantly confronted and threatened by competition from global brands in their home market (Ger, 1999). Therefore, both foreign and local retailers need a strategic and proactive approach to be globally competitive. Currently, consumers have greater disposable wages and spend their money more and more on products beyond basic necessities. Specially, consumers in emerging markets continue to show a strong preference for non-local brands from developed countries due to their perceived high quality and symbolic image (Batra et al., 2000). However, the performance of these brands has been mixed. In general, the relative market position of foreign brands is declining, and the advance of foreign brands in safe markets has halted, if not inverted. Consumers have different perceptions toward foreign and local brands, even within the same product category (Lee, Kumar, \& Kim, 2010). Local firms often use the appeal of globalness to market their products (Zhou \& Hui, 2007) and HTC is an example of such attempt. In addition to this, the world is shrinking into a global market place, so it is quite necessary to learn about consumer's perception toward global brands and factors influencing consumer purchase behavior.

When studying consumer references toward global brands, many researchers have emphasized the importance of perceived brand quality and perceived brand prestige factors through which perceived brand globalness indirectly affect consumer references (Shocker, Srivastava, \& Ruekert, 1994; Batra et al., 2000; Kinra, 2006; Zhou \& Hui, 2007). However, very few have been successfully done to test the mediation effects of these two important variables. To the best of our knowledge, there is no such a study that deals with this issued in the mobile phone industry. For this reason, this study's purpose is to investigate the effects of mediating variables on 
the relationship between the predictor and the outcome variables.

In so doing, this study aims at constructing an overall framework of relevant variables obtained from the given literature. Specifically, the research used perceived brand quality and perceived brand prestige as two mediator variables to examine the effects of perceived brand globalness on consumer purchase likelihood. This study conducted a survey on college students consisting of four universities in the central part of Taiwan to understand their perceptions of global brand versus local brand. The theory of Baron and Kenny (1986) together with structural equation modeling (SEM) approach was used as the methodology in this study to complete the discussed tasks.

\section{Literature Review}

The purpose of this section is to review critical factors that affect consumer preferences for global brands. Then, the fundamental concepts of those critical factors are discussed. Based on that, we propose six hypotheses for dealing with the research problem. Eventually, the conceptual framework of this study is proposed.

\subsection{Critical Factors that Influence Consumer Purchase Likelihood (CPL) for Global Brands}

Consumer purchase intention or consumer purchase likelihood is considered as a subjective inclination toward a product and can be an important index to guess consumer behavior (Fishbein \& Ajzen, 1980; Chi, Yeh, \& Yang, 2009). To determine factors that have a strong influence on consumer's perception toward global brands, a great number of studies have been done before, to name a few, Shocker et al. (1994), Batra et al. (2000), Kinra (2006), Zhou \& Hui (2007), and Steenkamp, Batra, and Alden (2003). Among them, Shocker et al. (1994) proposed that perceived brand globalness was one of the most important factors affecting consumer perception of brand superiority. In addition, perceived brand globalness has been highly connected with brand prestige and brand quality (Batra et al., 2000). Later, Steenkamp et al. (2003) identified that perceived brand prestige is the second factor driving global brand preference. Accordingly, they conducted a study on consumer preferences of global and local brand. In this study, the authors construct a research framework with three main pathways, thereby perceived brand globalness (PBG) affect consumer's purchase likelihood. The framed pathways were perceived brand quality (PBQ), perceived brand prestige (PBP), and the psychological benefits of PBG. As a result, PBG has a positive influence on both brand quality and brand prestige. Finally, through these pathways, PBG can indirectly affect consumer's purchase likelihood (Steenkamp et al., 2003).

\subsection{Perceived Brand Globalness (PBG)}

Basically, a local brand is sold and marketed (distributed and promoted) in a relatively small and limited geographical area. A local brand is a brand that can be found in only one country or zone. It may be called a zonal brand if the area encompasses more than one metropolitan market. It may also be a brand that is developed for a specific local marketplace; however, an interesting thing about local brands is that the local branding is more often done by consumers than by the producers. So, local brands are distinct as brands that exist in one country or in a limited environmental region (Wolfe, 1991; Schuiling \& Kapferer, 2004; Eckhardt, 2005).

According to Yu and Dong (2010), the term "global brand" is one which is perceived to reflect the same set of values around the world. Global brands transcend their origins and create strong substantial relationships with consumers across countries and cultures (Johansson \& Ronkainen, 2004). Where a customer buys one new global product is not important, because the customer feels the same thing about the product. Global branded products having this image in and around the world offer similar quality products. Examples of global brands include Facebook, Apple, Pepsi, McDonald's, Sony, Nike and so forth. These brands are used to sell the same product across multiple markets and can be considered successful to the extent that the associated products are easily recognizable by the diverse sets of consumers.

\subsection{Perceived Brand Quality (PBQ)}

Perceived Brand Quality is found to be the most important predictor for the pathway between perceived brand globalness and the consumer purchase likelihood in comparison with perceived brand prestige (Steenkamp et al., 2003). Therefore, it is suggested that brand quality should be primarily focal strategy key for global brand managers.

Aaker (1991) defined perceived quality as the customer's perception of the overall quality or superiority of a product or service in term of its intended purpose, relative to alternatives. Strizhakova, Coulter, and Price (2011) developed two models with two specific mediating variables namely brand and self-identity brand signal to identify the global brand preferences of consumers. They found that consumers in both developed and developing countries prefer global brands due to higher quality. 
Therefore, quality is a main factor affecting customer perception and underlying the long-term success of products and firms (Mitra \& Golder, 2006). It thus differs from actual or objective quality. Perceived quality should not be mistaken with the nature and quantity of ingredients, features, or service of a product. At the same time, perceived quality should be distinguished from manufacturing quality and the zero defect goal (Aaker, 1991). Thus, perceived brand quality can be defined as the customer's perception of the overall quality or superiority of a product or service with respect to its intended purpose, relative to alternatives.

\subsection{Perceived Brand Prestige (PBP)}

Early, perceived brand prestige was found to be the second driving force between perceived brand globalness and consumer purchase likelihood (Steenkamp et al., 2003). The concept of prestige may mean different things to different consumers. The general conjecture is that prestigious brands are infrequently purchased. Therefore, they require a higher level of interest that strongly relates to an individual's self-concept. A consumer's perceived prestige image of a brand is produced from a multitude of interactions between the consumer and different factors within the environment; therefore, it is expected that different consumers would have different perceptions of prestige levels for the same brand.

Consumers improve their perceptions of a product's prestige based on interactions with the product, object properties (e.g., appearance), pleasurable values and emotional attraction (Vigneron \& Johnson, 1999). Perceived brand value related with the product provides satisfaction. If consumers feel the product gives more satisfaction, which will affect consumers' perceived brand value.

\subsection{Consumer Purchase Likelihood (CPL)}

Regarding this topic, Gielens and Steenkamp (2007) carried out a study on the effect of a new product on consumers. They found that a new product acceptance is related to company's brand reputation factors. In other words, consumers demonstrated higher preferences for a new product if a company introduces a product by a brand with more market power and reputable brand name across the all these countries. Consumers make many buying decisions every day, and the buying decision is the focal point of the marketer's effort (Armstrong \& Kotler, 2011). Furthermore, these two authors proposed five stages of the buyer decision process which consisted of need for recognition, information search, evaluation of alternatives, purchase decision, and post purchase behavior. Steenkamp et al., (2003) suggested two pathways, namely, the perceived brand quality and brand prestige, through which PBG affects CPL. The first pathway, indicates a positive relationship between PBG and PBQ, which upwardly affects brand purchase likelihood. Global brand perception has an effect on consumer purchase likelihood. The second pathway indicates a positive relationship between PBG and PBP which upwardly affects brand purchase likelihood. Their research found the influence of perceived brand quality to be stronger on consumer purchase likelihood. However, studies from developing countries have found different effects. This means research results are related to participants' social life and products. Therefore with the same research questions, in different countries, we can find different results. Specifically, consumers from developing countries tend to use the ownership and/or consumption of global brands to increase their social status and strengthen self-identity of being a worldly consumer (Batra et al., 2000). Those theoretical models were focused on global brand perception and positioning which might play an important role in purchasing behavior (Steenkamp et al., 2003; Strizhakova, 2011).

In short, higher quality and higher prestige of a global brand are the pathways through which perceived brand quality can indirectly affect consumer purchase likelihood. For these reasons, this study used perceived brand quality and perceived brand prestige as mediation factors to identify the above mentioned relationship. Existing research indicated that PBG not only can directly influence CPL, but also indirectly affect CPL through PBQ and PBP (Han, 1990; Steenkamp et al., 2003). Based on those findings, this paper built the research hypotheses. The next two sections will look at "direct" and "indirect" effects pf PBG.

\subsection{Hypotheses and Research Framework}

\subsubsection{Effect of PBG on PBQ}

In the past, in both developed and developing countries, consumers had seen a global brand as a symbol of high quality due to its premium price and global acceptance (Batra et al., 2000; Bhardwaj at el., 2010; Keller, 1997; Kapferer, 1997). Recently, the conception about high perceived quality of global brand has continued to be supported in some typical studies like Milberg and Sinn (2008) or Steenkamp et al. (2003). Then, in this paper we also support this notion of a global brand to build the hypothesis 1 is proposed as follows:

H1: Perceived brand globalness positively affects consumers perceived brand quality. 


\subsubsection{Effect of PBG on PBP}

A global brand often has higher prestige than a local brand due to its scarcity and premium price (Bearden \& Etzel, 1982; Batra et al., 2000). These high scarcity and high price are just the two reason make a greater Batra aspirational and prestige appeal (Bearden \& Etzel, 1982). Overtime, many scholars states that PBG leads to a higher brand prestige, but to the best of our knowledge, there is no paper empirically test this relation with respect to the smart phone industry. This study therefore uses the following hypothesis to fill the research gap.

H2: Perceived brand globalness positively affects consumers perceived brand prestige.

\subsubsection{Effect of PBG on CPL}

According to Steenkamp et al. (2003), a global brand has its ability to impact on the consumers' propensity toward purchase likelihood. In addition, an added value can be created in consumers' mind when a brand is perceived as global. Therefore, higher perception of brand globalness may result in higher consumers purchase likelihood.

H3: Perceived brand globalness positively affects consumers purchase likelihood.

\subsubsection{Effect of PBQ and PBP on CPL}

Existing studies indicate that PBQ and PBP for a global brand could influence CPL due to the fact that, in addition to quality, a global brand represents high prestige or social status (Shocker et al., 1994; Batra et al., 2000). Furthermore, in the empirical study done by Steenkamp et al. (2003), quality and prestige are two factors driving consumers' purchase intention of a global brand. Thus, it can be concluded that PBQ and PBP of a global brand will strongly affect CPL as stated in the following hypotheses.

H4: Perceived brand quality positively affects consumers purchase likelihood.

H5: Perceived brand prestige positively affects consumers purchase likelihood.

\subsubsection{Effect of PBG on CPL via the PBQ and PBP mediators}

As mentioned earlier, two indirect pathways have been introduced by Steenkamp et al. (2003) to examine the mediating roles of PBQ and PBP. Empirical studies in developed countries showed that PBQ has a stronger effect on CPL than PBP. However, this might be different in developing countries, like Taiwan, and specially related to the smart phone industry. Furthermore, owning global brands to prove self-social status have been a trend for consumers in developing world. Therefore, we proposed the following hypothesis with the aim to explore the influence of PBG on CPL through pathways of PBQ and PBP.

H6: Perceived brand quality and perceived brand prestige mediate the influence of perceived brand globalness on consumer purchase likelihood.

As discussed earlier, the theoretical framework was built mainly based on the research proposal and the review of literature in the given field. The whole model is illustrated in Figure 1 including six hypotheses which were later used to test the research model.

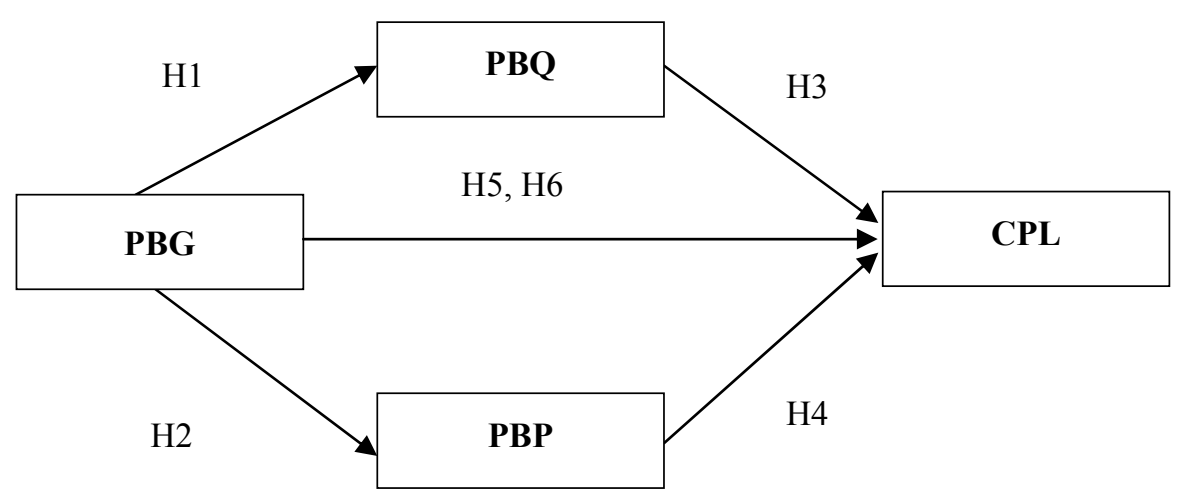

Figure 1. The theoretical framework 


\section{Methodology}

\subsection{Data Collection}

This research uses the primary data collected by the structured questionnaire. All scales concerning the PBG, PBQ, PBP, and CPL are based on a seven-point Likert scale (from strongly disagree to strongly agree). The population of this study includes Taiwanese consumers in Central Taiwan and the target sample was focused on colleague students. College students were selected because studies indicated that consumers in this group are more willing to purchase global brand products (Lukose, 2005; Dou, Wang, \& Zhou, 2006). A total of 475 questionnaires were distributed to predetermined participants, and 452 (95.1\%) questionnaires were collected. Among those, 13 participants did not respond to all questions, so a total of $439(92.4 \%)$ questionnaires were used in the final sample.

\subsection{Testing for the Mediation}

Generally, a mediator is described as the mechanism through which one variable (a predictor) influences another variable (an outcome variable) although there is a various ways to define a mediator variable. Adapted from Baron and Kenny (1986) and Tavakoli et al. (2009), the objective of this section is to review briefly four steps of mediation testing applied to the theoretical model.

The theoretical model was constructed based on the study's purpose and the review of relevant literature. As a result, there were one predictor variable, one outcome variable, and two mediating variables in the research model. Particularly, in the theoretical model, perceived brand globalness (PBG) plays the role of an independent variable and customer purchase likelihood (CPL) is a dependent variable. Accordingly, perceived brand quality (PBQ) and perceived brand prestige (PBP) are the mediating variables through which PBQ indirectly influences on CPL In order to investigate the mediation effects in this study, the research model were broke in in two causal chains as indicated in figure 2 and figure 3.

The first chain shows that PBG affects PBQ, PBQ in turn affects CPL. Similarly, the second chain describes PBG affects CPL though PBP. The intervening variables, PBQ and PBP, are the mediators. They "mediate" the relationship between a predictor (PBG) and an outcome (CPL). These relationships are summarized in table 1 .

In the above diagrams, paths a ( $\left.\mathrm{a}^{\prime}\right)$ and path $\mathrm{b}\left(\mathrm{b}^{\prime}\right)$ represent direct effects. The meditational effect, in which PBG leads to CPL through PBQ (PBL), is called the indirect effect. To test indirect and direct effect, Regression is considered as one of the most famous techniques to complete these tasks. This study therefore used four-step method which was proposed by Baron and Kenny (1986) to identify whether mediator effects exist in the conceptual model or not. This four-step approach is summarized in Table 1.

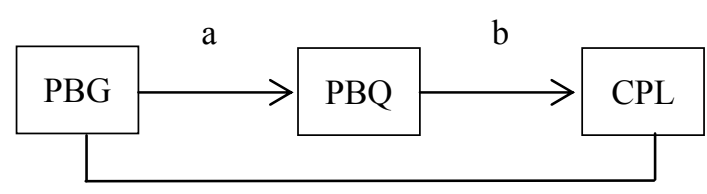

C

Figure 2. The first causal chain

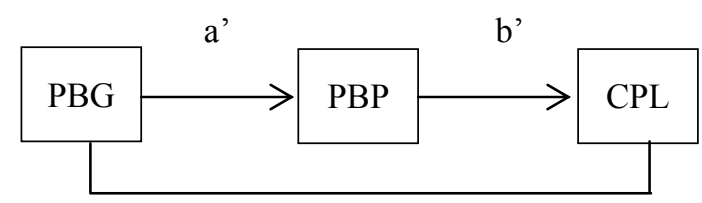

C

Figure 3. The second causal chain

Table 1. Four step of mediation testing for the research model

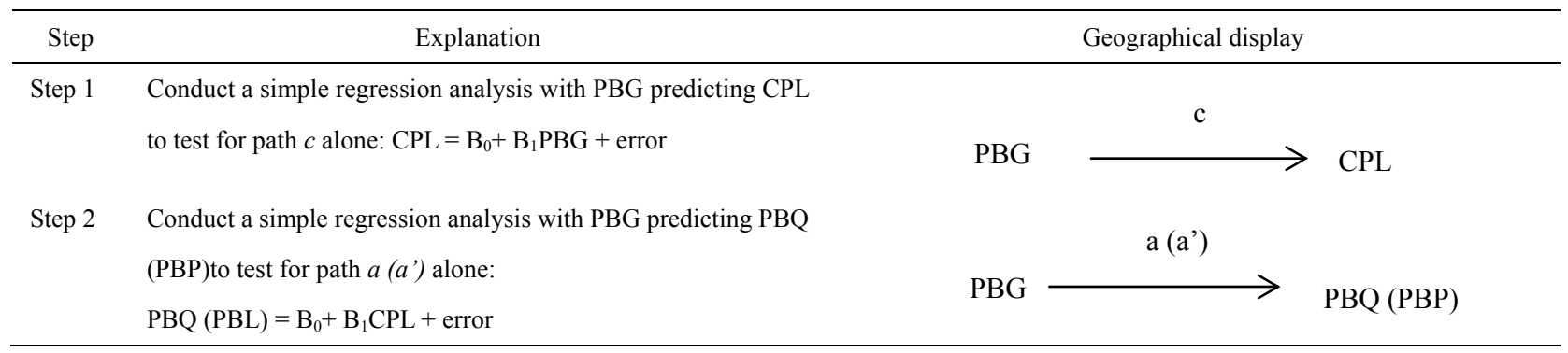




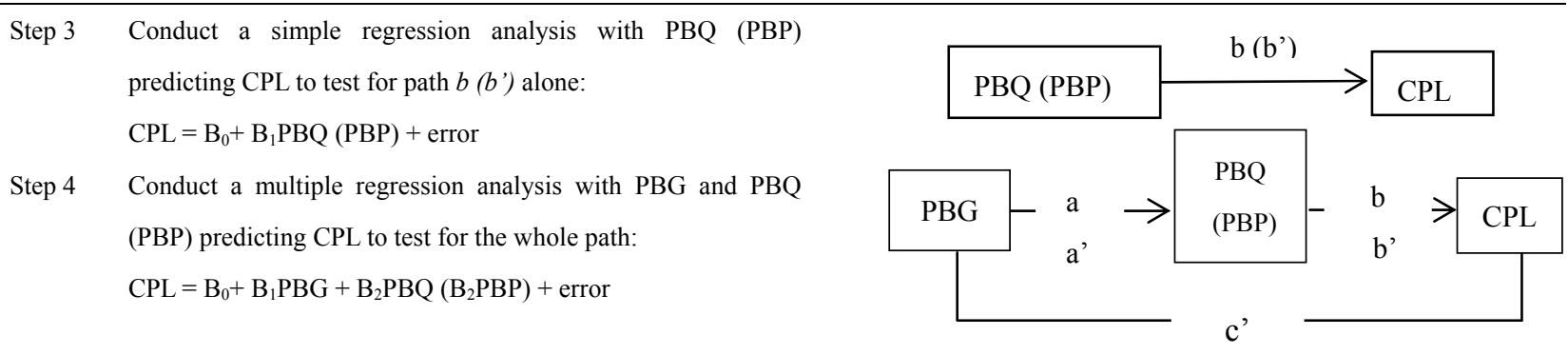

Step 1 to step 3 allow us to set up the zero-order relationships among existing variables. If any of the tests in steps 1 to 3 result non-significant, we can conclude that mediation does not exist (MacKinnon, Fairchild, \& Fritz, 2007) and there is no need for further investigation. If significant relationships exist from step 1 to step 3 , then we can move to step 4. If in step 4 the mediation effect (path c') still remains significant, but considerably lower, after controlling for the predictor, we can conclude that partial mediation exist. Full mediation is supported if the predictor variable is no longer significant when mediator is included in the model. In short, after reaching step 4 (Table 1), if $\mathrm{c} \approx \mathrm{c}^{\prime}$, then there is no mediation; if $\mathrm{c}>\mathrm{c}^{\prime}$, there is partial mediation; and if $\mathrm{c}^{\prime}$ is not significant, then there is full mediation (Fairchild \& McQuillin, 2010).

\section{Results}

\subsection{Sample Characteristics}

A total of 439 (92.4\%) usable questionnaires collected from Taiwanese university students were included in the final sample. The demographic data collected including gender, age, education, and income is shown in Table 2. The age of the respondents ranged from 18 to 25 years old, which meets the study's purpose for young target sample. With regard to participants' gender, it was skewed with $65.1 \%$ of the respondents being female and $34.9 \%$ being male. In terms of education, the sample was skewed with up to $98.6 \%$ being undergraduate level and only $1.4 \%$ being graduated students, which also meet the study's aim. The participants' monthly incomes were mostly less than 6,000 NT\$ (US\$200) (70.4\%) or between 6,000-15,000NT\$ (US\$200-\$500) (25.1\%). It is a common phenomenon as college students' financial sources are mostly conditional up on their family. However this is not a big issue for them to spend money on new global and local brands. In eastern culture it is not uncommon for parents to support their children during their undergraduate university studies.

Table 2. Gender and age of the participants

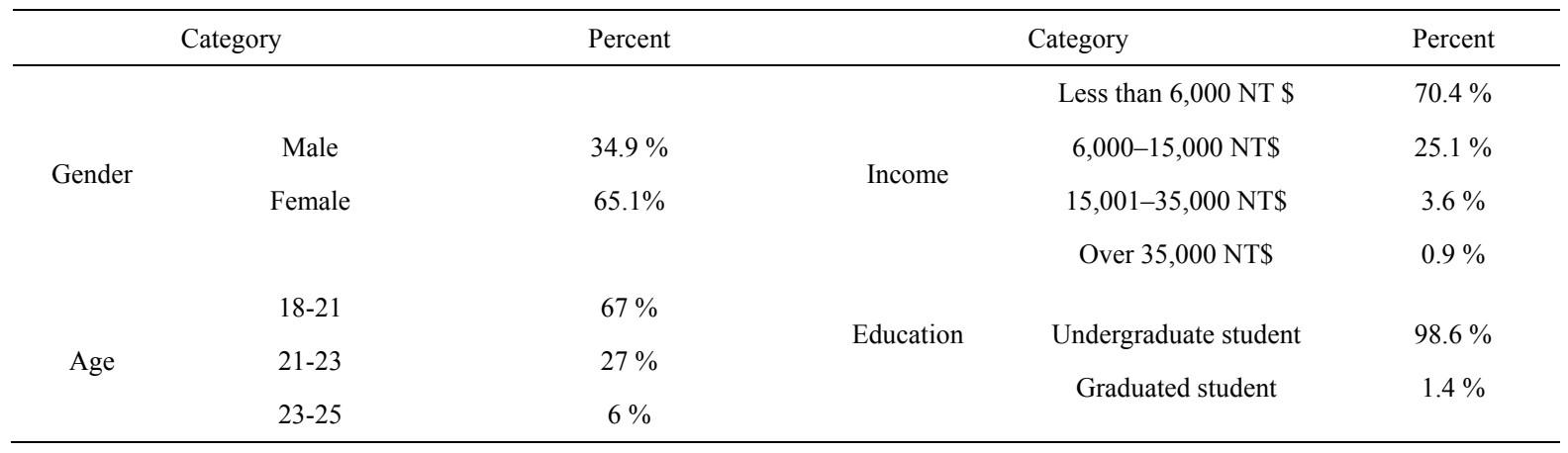

\subsection{Validity and Reliability Test}

Preparation of the data analysis using SEM requires that the measures used in the study be refined in order to contain only those items that are the most relevant, valid and reliable. Careful measure refinement insures a theoretically sound and well-fitting model. All of the measures in the study were examined by checking their unidimensionality and reliabilities and by performing the Exploratory Factor Analysis (EFA), the Reliability Analysis, and the Confirmatory Factor Analysis (CFA). Once the measurement model (final CFA) was accepted, the SEM was tested by using the AMOS software.

\subsubsection{Validity Test-EFA}

Factor analysis refers to a variety of statistical techniques whose common objective is to represent a set of 
variables in terms of a smaller number of hypothetical variables (Jae-On \& Mueller, 1978). The extraction method is Principal Component Analysis; it means that only those factors with eigenvalues greater than 1 will be extracted. Meanwhile, we conducted varimax rotation to achieve simple structure by focusing on the columns of the factor loading matrix. The Statistical Package for Social Science (SPSS 20) was utilized to carry out the factor analysis. As shown in Table 3, the KMO test for all variables is 0.822 (much higher than .50) which is great at the confident interval level of $\mathrm{P}$ value $<.05$ (Kaiser, 1974). Furthermore, the factor loading of four factors are all greater than .50. Four factors extracted account for $67.13 \%(>50 \%)$ of the variability (Field, 2005). The results of factor analysis indicate that the data is valid and meets the requirements to be used for further analyses.

\subsubsection{Reliability Test}

After Factor analysis, the Reliability test for each construct was carried out. Reliability, as defined by Kerlinger and Lee (2000), is the lack of distortion or precision of a measuring instrument. Cronbach's alpha reliability coefficient was conducted to measure reliability of the data. According to Sekaran (2000), if the value of coefficient alpha is between .6 and .8 the instrument is considered reliable and higher than .8 is considered highly reliable. The results presented in Table 3 show that the variables of PBQ, PBP, PBG, and CPL measures were deemed acceptable because the associated reliability coefficients were greater than .50 . In other words, the reliability of the measures is acceptable.

Table 3. Expletory factor analysis and reliability results

\begin{tabular}{|c|c|c|c|}
\hline Variables & Item & Factor loading & Cronbach's Alpha \\
\hline \multirow{4}{*}{ Perceived Brand Quality } & PBQ1 & .77 & \multirow{4}{*}{.83} \\
\hline & PBQ2 & .76 & \\
\hline & PBQ4 & .78 & \\
\hline & PBP3 & .92 & \\
\hline \multirow[t]{2}{*}{ Perceived Brand Prestige } & PBP4 & .95 & \multirow[t]{2}{*}{.94} \\
\hline & PBP5 & .67 & \\
\hline \multirow{2}{*}{ Perceived Brand Globalness } & PBG2 & .73 & \multirow{2}{*}{.71} \\
\hline & PBG3 & .62 & \\
\hline \multirow{4}{*}{ Perceived Brand Likelihood } & CPL1 & .69 & \multirow{4}{*}{.82} \\
\hline & CPL2 & .70 & \\
\hline & CPL3 & .80 & \\
\hline & CPL4 & .75 & \\
\hline Cronbach's Alpha & \multicolumn{3}{|c|}{.83} \\
\hline KMO & \multicolumn{3}{|c|}{$.82>.5$} \\
\hline P-Value & \multicolumn{3}{|c|}{$.000<.05$} \\
\hline Cumulative \% & \multicolumn{3}{|c|}{$67.13 \%>50 \%$} \\
\hline
\end{tabular}

\subsection{Data Analysis}

\subsubsection{Confirmatory Factor Analysis (CFA)}

In the confirmatory factor analysis process, the researcher works to improve the overall fit of the model (DeCoster, 1998). This procedure involves ensuring unnecessary items and correlating similar items. In a confirmatory factor analysis, all of the variables in the model are co-varied, although there is no excepted relationship between variables. Therefore, the confirmatory factor analysis included all of the variables in the proposed model.

CFA was performed to examine the relationship between the items and their respective latent variables using AMOS 20. Relationships between the constructs and their latent variables were specified in the measurement model (Table 4). The CFA results indicated that Chi-square / Degrees of freedom (X2/df) ratio was 4.27 which complied with the criteria of X2/df $<5$ (Chin \& Todd, 1995). A chi square test functions as a statistical method 
for evaluating models. The fit index is more descriptive than statistical. Fit indexes describe and evaluate the residuals that result from fitting a model to the data. A chi square probability value greater than .05 indicates acceptable model fit (Table 8).

The GFI (goodness of fit index) $=.94$ and the AGFI (adjusted goodness of fit index) $=.90$, these result meet the criteria of being bigger than .80 suggested by Baumgartner and Homburg (1996). According to Brown (2006), the comparative fit index (CFI) should be equal to or greater than .90 to indicate well fit. In this study, the CFI was .96 which was considered great. In addition, there is adequate fit if the root mean square error of approximation (RMSEA) is less than or equal to .08 (Hair et al., 1998). In this paper, the RMSEA was .078 $(<.08)$. In short, the result of the CFA shows a great model as indicated in table 7.

Table 4. Model fit analysis

\begin{tabular}{|c|c|c|c|c|c|c|c|}
\hline Model & $\mathrm{X}^{2}$ & $\mathrm{df}$ & $\mathrm{X}^{2} / \mathrm{df}$ & GFI & AGFI & $\mathrm{CFI}$ & RMSEA \\
\hline & 204.727 & 48 & 4.265 & .94 & .90 & .96 & .078 \\
\hline & \multicolumn{2}{|c|}{ Suggested Value } & $<5$ & $>.90$ & $>.90$ & $>.90$ & $<.08$ \\
\hline
\end{tabular}

\subsubsection{Convergent Validity}

To deal with convergent validity, Aderson and Gerbling (1988) suggested using three common indices to evaluate the measurement model. Those are the individual item reliability, the composite reliability (CR) and the average variance extracted (AVE). Firstly, in this study, the factor loadings of the measurement items for each latent variable were significant for convergent validity with the lowest being $0.53>0.5$ (CPL4), so these results show a high degree of reliability (Hair, Anderson, Tatham, \& Black, 1998) (Table 5).

Table 5. Factor loadings of the measurement items

\begin{tabular}{ccccccccccccc}
\hline Item & PBQ1 & PBQ2 & PBQ4 & PBP3 & PBP4 & PBP5 & PBG2 & PBG3 & CPL1 & CPL2 & CPL3 & CPL4 \\
\hline Factor & .87 & .88 & .63 & .89 & .97 & .79 & .72 & .80 & .81 & .92 & .64 & .53 \\
Loading & & & & & & & & & & & \\
\hline
\end{tabular}

Secondly, the composite reliability (CR) is applied to test the internal consistency of each latent variable. The results of CR were calculated (Table 6). The CR value of each latent variable is between .71 and .93. The CR with the value greater than 0.6 is considered being indicative of strong internal consistency (Fornell \& Larker, 1981; Hair et al., 1998; Malek, 2012). Finally, we used the average variance extracted (hereinafter referred to AVE) to measure the degree of explained variance attributable to the measurement items of these variables. The AVE values were ranged from .55 to .84 . These AVE estimates all exceeded the suggested criteria of .50 (Fornell \& Larker, 1981). Therefore, the results of the above analysis allow us to conclude that the latent variables of PBQ, PBP, PBG, and CPL have a strong reliability and convergent validity (Table 6).

Table 6 . Test of composite reliability and convergent validity

\begin{tabular}{lccc}
\hline \multicolumn{1}{c}{ Variable } & Abbreviation & CR & AVE \\
\hline Perceived Brand Quality & PBQ & .85 & .66 \\
Perceived Brand Prestige & PBP & .93 & .84 \\
Perceived Brand Globalness & PBG & .71 & .56 \\
Consumer Purchase Likelihood & CPL & .83 & .55 \\
\multicolumn{1}{r}{ Accepted Value } & & $>.70$ & $>.50$ \\
\hline
\end{tabular}




\subsubsection{Discriminant Validity}

In this part, the discriminant validity was tested to identify whether a construct is truly distinct from other constructs. Fornell and Larcker (1981) suggested comparing the AVE's square root with the correlation coefficients of latent variables. The findings showed that the square root of AVE are all higher than 1 (Table 7) which means the indicators have more in common with the construct they are associated with than they do with other constructs. In other words, four constructs of CFA model indicate strong discriminant validity.

Table 7. Test of discriminant validity

\begin{tabular}{lcccc}
\hline \multicolumn{1}{c}{ Variable } & PBQ & PBP & PBG & CPL \\
\hline Perceived Brand Quality (PBQ) & 1 & .19 & .34 & .72 \\
Perceived Brand Prestige (PBP) & .19 & 1 & .44 & .20 \\
Perceived Brand Globalness (PBG) & .34 & .44 & 1 & .39 \\
Perceived Brand Likelihood (CPL) & .72 & .20 & .39 & 1 \\
Max correlation & .72 & .44 & .44 & .72 \\
VAVE & .81 & .92 & .75 & .74 \\
VAVE / Max. Correlation & 1.13 & 2.09 & 1.70 & 1.03 \\
\hline
\end{tabular}

\subsection{Structural Model}

The results of the CFA analysis indicated that each construct of the research model has a strong reliability, convergent validity, and discriminant validity. Therefore, it is suitable for the study to use a structural model. As discussed earlier, SEM is used to test the overall good-of-fit and determine the relationships among variables.

Table 8. Results of SEM analysis

\begin{tabular}{lllccccccc}
\hline Model & $\mathrm{X}^{2}$ & $\mathrm{df}$ & $\mathrm{X}^{2} / \mathrm{df}$ & $\mathrm{GFI}$ & AGFI & \multicolumn{1}{c}{ CFI } & \multicolumn{2}{c}{ RMSEA } & NFI \\
\hline & 190.58 & 49 & 3.89 & .94 & .91 & .96 & .07 & .94 \\
& Accepted value & $<5$ & $>.90$ & $>.90$ & $>.90$ & $<.08$ & $>.90$ \\
\hline
\end{tabular}

As shown in Table 8 , the value of $\mathrm{X} 2 / \mathrm{df}=3.89$, which complied with the suggested criteria of $<5$. In addition, the values of GFI $=.99$ and AGFI $=.91$ are greater than suggested criterion (Hair et al., 1998; Baumgartner \& Homburg, 1996). RMSEA $=0.074$ is less than suggested criterion (Hair et al., 1998). CFI $=0.958$ and NFI $=$ 0.94 (Bentler, 1992). These results indicate a very good fit between the conceptual model and the empirical model in this study.

Table 9. Results of the hypotheses

\begin{tabular}{|c|c|c|c|c|c|}
\hline Hypothesis & Path & $\beta$ & S.E & $\mathrm{P}$ & Result \\
\hline H1 & $\mathrm{PBG} \rightarrow \mathrm{PBQ}$ & $.36 * * *$ & .06 & .00 & Supported \\
\hline $\mathrm{H} 2$ & $\mathrm{PBG} \rightarrow \mathrm{PBP}$ & $.46 * * *$ & .07 & .00 & Supported \\
\hline H3 & $\mathrm{PBP} \rightarrow \mathrm{CPL}$ & .07 & .04 & .87 & Rejected \\
\hline $\mathrm{H} 4$ & $\mathrm{PBQ} \rightarrow \mathrm{CPL}$ & $.65 * * *$ & .05 & .00 & Supported \\
\hline H5 & $\mathrm{PBG} \rightarrow \mathrm{CPL}$ & $.24 * * *(\mathrm{w} /$ mediation $)$ & .06 & .00 & Supported \\
\hline H6 & $\mathrm{PBG} \rightarrow \mathrm{CPL}$ & $\begin{array}{l}.43 * * * \\
\text { (w/o mediation) }\end{array}$ & .06 & .00 & Supported \\
\hline
\end{tabular}

\footnotetext{
$* * * \mathrm{P}<.001$
} 
Table 9 indicates that $\mathrm{H} 3$ was rejected while the other five hypotheses were supported. There is a positively and statistically significant relationship between PBG and PBQ (.36). PBQ in turn positively influence CPL (.65). The relationship between PBG and CPL with the mediating variables is (.24) and without mediation is (.43). The direct relationship between PBG and PBP is statistically significant (.46), however the relationship between $\mathrm{PBP}$ and CPL did not reach the confidence interval level of $\mathrm{P}<.05$ and is very small $(.07, \mathrm{P}=.87)$ (Figure 4$)$.

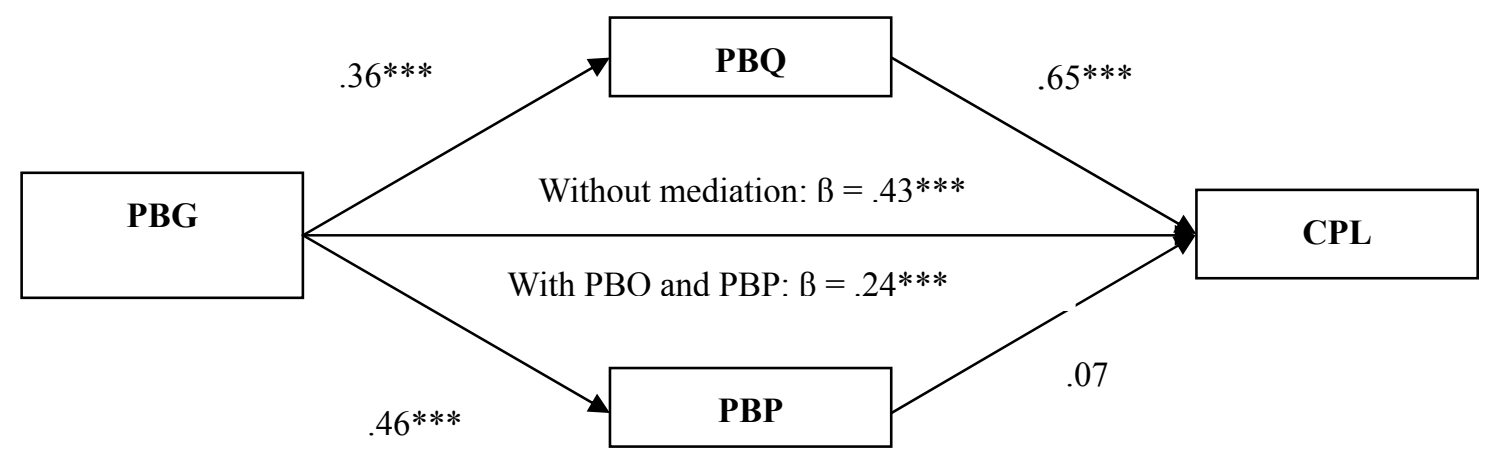

Figure 4. Testing the whole model with PBP and PBQ

Note: $* * * \mathrm{P}<.001$.

\subsection{Testing for Mediation Effect Using Post Hoc Analysis}

In this part we adopt Post Hoc analysis approach together with the SEM to test the mediating effects of Perceived Brand Quality and Perceived Brand Prestige in the study's model based on four steps that have been discussed in the methodology section.

As we can see in the conceptual model (Figure 3), mediations in this study were hypothesized in two causal chains in which PBG played the role of an independent variable (predictor), PBQ and PBP were the mediating variables, and CPL is a dependent variable (the outcome). Therefore, the model consisted of two pathways. The first pathway includes PBQ through which PBG affects CPL and the second pathways consists of PBP whereby PBG affects CPL. The following sections will discuss further post hoc analysis of the mediation.

\subsubsection{Test for Mediating Effect of Perceived Brand Quality}

Based on four steps which were outlined before, the study first established that PBG (the predictor) was related to CPL (the outcome) by regressing CPL on PBG variable (step 1) as shown in Table 9. As a result, the relationship between PBG and CPL was significant at the confidence interval level $\mathrm{P}$ value $<.001(\beta=.43$, $\mathrm{P}<.00$ ). In other words, path $\mathrm{c}$ was significant and the requirement for mediation effect was supported in step1. We moved to step 2 (path a) with the second equation. In this step, the mediating variable (PBQ) was regressed on the predictor variable (PBG). The findings shows the significant relationship between the mediator and predictor at the confident interval level $\mathrm{P}$ value $<.001(\beta=.38)$. Therefore, the requirement for step 2 was met. Accordingly, Step 3 were carried out to test the significant relationship between the mediator variable PBQ and the outcome variable CPL. The results indicated that PBQ has a highly significant relationship with CPL $(\beta=.65$, $\mathrm{P}<.00$ ), thus path $\mathrm{b}$ was significant or the conditions for step 3 was satisfied (Table 10).

Table 10. Test for mediating effect of PBQ and PBP

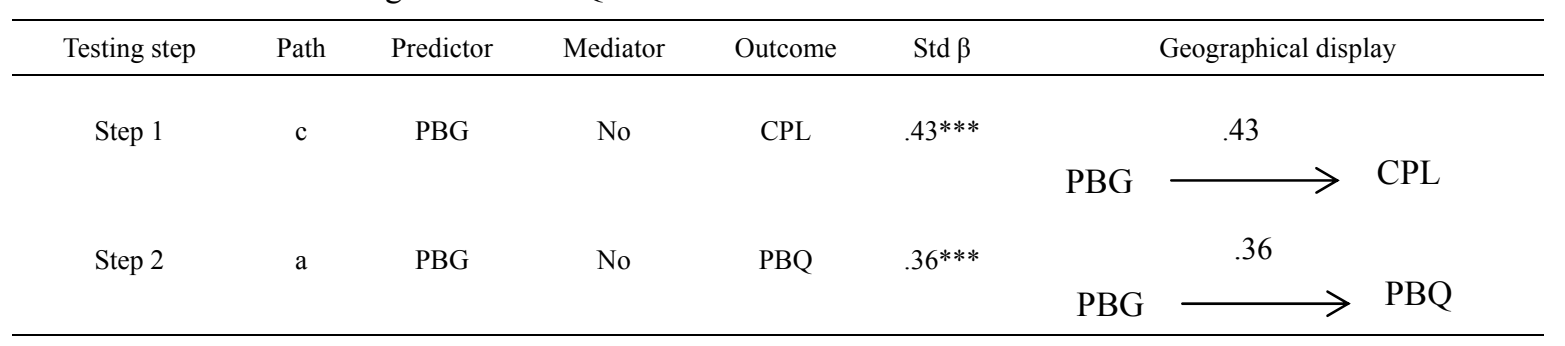




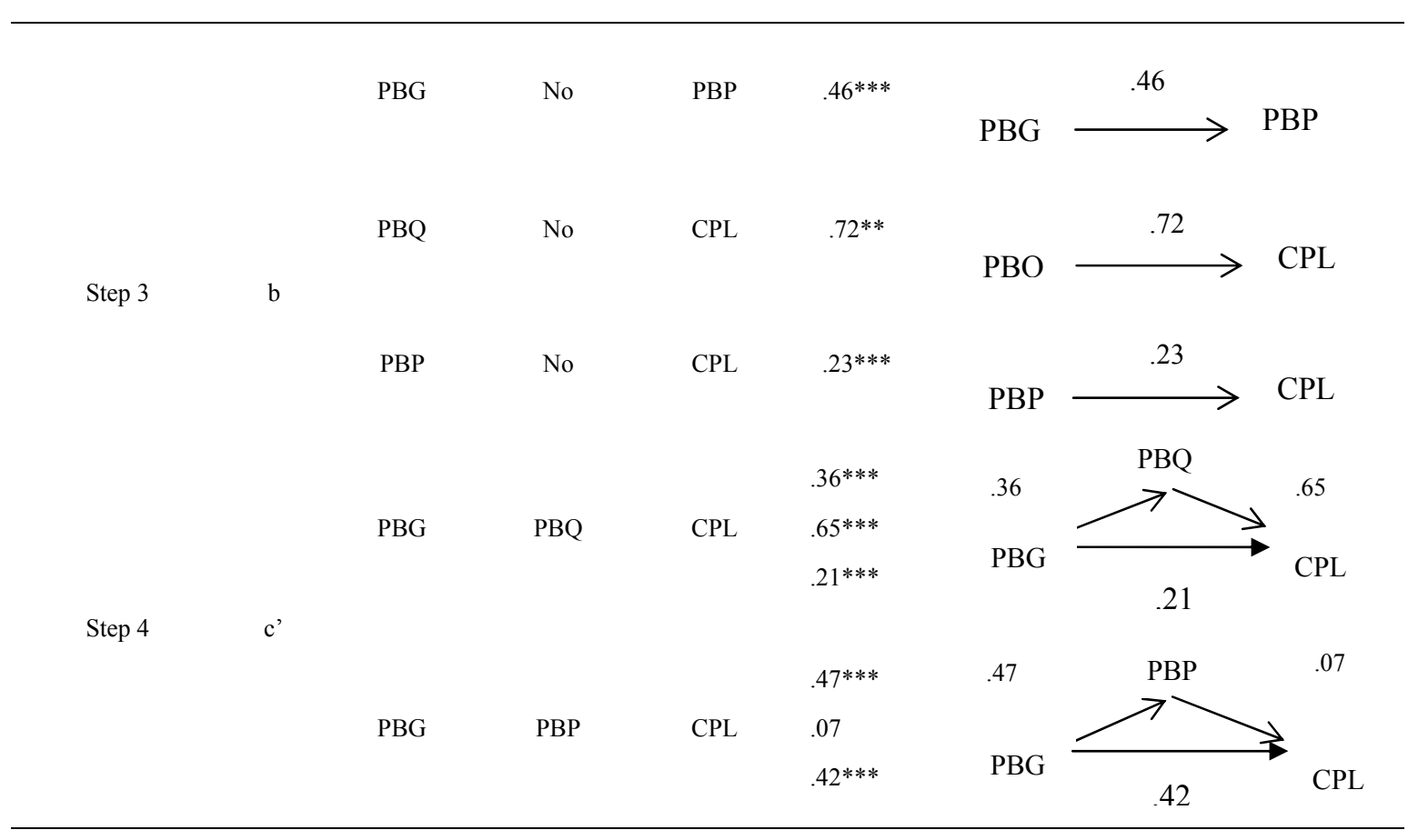

$* * * \mathrm{P}<.001 ; \operatorname{Std} \beta=$ standardize beta coefficient.

The successes in step 1, 2, 3 allow us to continue our work on step 4 with all three variables involving in the model. Specifically, this step involved regressing the outcome variable (CPL) on the predictor variable (PBG) and mediator variable (PBQ). Results of step 4 are showed in Figure 5 where the relationship between the predictor and the outcome still remained the positively significant $((\beta=.21, \mathrm{P}<.00)$ with the standardized beta coefficient reduced from .43 to .21 which compiled with the requirement that the influence of predictors on outcome variables must be weaker than that of step 1 (path $\mathrm{c}<$ path $\mathrm{c}^{\prime}$ ). In addition, there is a significant relationship between mediator variable PBQ and outcome variable CPL $(\beta=.65, \mathrm{P}=.00)$ or the significant effect become stronger with mediation controlled. Therefore, it could be concluded that there was a partial mediation effect of PBQ in the research model through which PBG influenced CPL (Figure 5).

Without mediation: $\beta=.43 * * *$

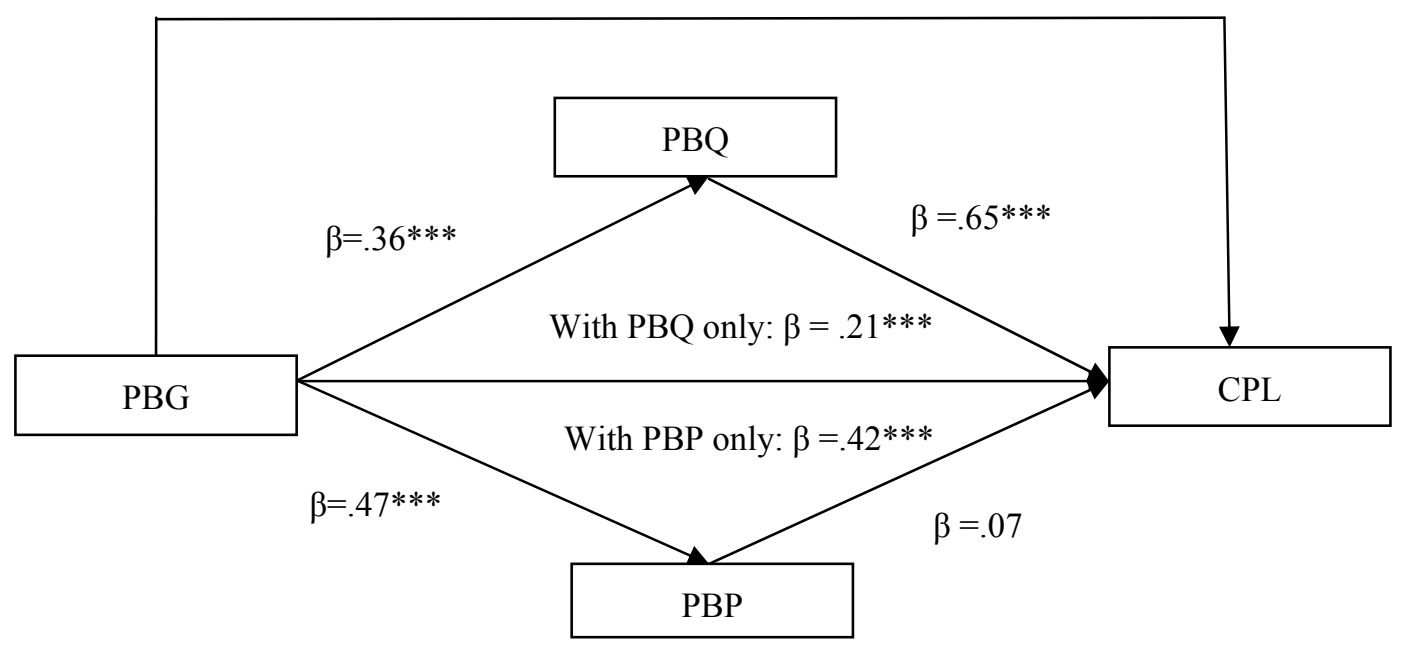

Figure 5. Results of mediation test for PBQ and PBP separately

Note: $* * * \mathrm{P}<.001$ 


\subsubsection{Test for Mediating Effect of Perceived Brand Prestige}

Analogous to the last section, we also used four-step approach to test the mediation effect of Perceived Brand Prestige in this phase. The results were indicated in table 9 which showed that the requirements for step 1, step 2, and step 3 were met because there were the positively significant influences of the predictors on the outcome at the confident interval level $\mathrm{P}<.001$. In other words, path $\mathrm{a}, \mathrm{b}$, and $\mathrm{c}$ were supported, so step 4 was carried out to test if the mediator PBP works or not.

The results are summarized in Figure 5 where the standardized beta coefficient is slightly decreased from .43 (without mediation controlled) to .42 (with mediation controlled). This met the condition that the influence of predictors on outcome variables must be weaker than that of step 1 (path $\mathrm{c}<$ path $\mathrm{c}^{\prime}$ ). However, there was no significant relationship between the mediator and the outcome variable $(\beta=.07, \mathrm{P}=.85)$. Obviously, PBP did not play the role of a mediator in the study model. In short, the results of the post hoc analysis indicate that perceived brand quality has a mediating effect on the relationship between perceived globalness and consumer purchase likelihood while perceived brand prestige does not mediate the relationship between the PBG and CPL.

\section{Conclusions, Limitations and Future Research}

Perceived brand globalness has been considered a key vehicle that directly or indirectly draws consumer's purchase likelihood in the past decade. While there have been a number of studies dealing with the direct relationship between perceived brand globalness and consumer's purchase likelihood, indirect relationships are still scarce. To the best of our knowledge, this paper is the first to examine the indirect relationship between perceived brand globalness and consumer's purchase likelihood applied to mobile phone industry. In doing so, perceived brand quality and perceived brand prestige, the two most typical dimensions that lead to a consumer's purchase likelihood, were used as mediating channels in this study. As a result, consumer's purchase intention in mobile phone industry could basically be explained through the path way in which perceived brand quality plays the role of a mediator variable through which the element of perceived brand globalness will influence consumer purchase likelihood. It can be understood that, perhaps, Taiwanese college student consumers still have not perceived the HTC Company as a full global company. Their main concern about the HTC's product is the quality. In short, Taiwanese college consumers are more interested in keeping up with the world of fashion. They are willing to purchase high quality foreign famous brands at high prices. According to the above analyses, Taiwanese customers consider quality is more important than prestige when they purchase mobile products of the HTC Company.

\subsection{Theoretical Implications}

The theoretical implications of this study are to address the research gap in the given field by providing the new findings. As existing studies indicate that there was a significant relationship between perceived brand globalness and consumer purchasing likelihood. In addition, the strong theoretical and empirical support for a relationship between perceived brand quality and perceived brand prestige was also found in the literature. Therefore, this study attempted to test previously developed theory in the context of perceived brand quality and prestige on how to influence consumer purchasing likelihood in the mobile market in Taiwan. However, the findings of this study present that not all above literature were supported in this study. In contrast, this study found that there was not a significantly direct relationship between perceived brand globalness and consumer purchasing likelihood. Furthermore, perceived brand prestige did not work well as a mediating variable. Therefore, the findings of this study help to construct the process of organizing a framework for completely understanding consumer purchase intention toward global brands. Eventually, this study also contributes to an established body of literature about important and timely variables within the mobile phone industry.

\subsection{Limitation and Suggestions for Future Research}

Although the authors strongly believe that the study provides insightful empirical findings, there are some limitations in this study that should be noted. This study was not able to draw the whole picture in the given industry. Future research should focus more on previous works to identify other factors that may efficiently explain consumer purchase likelihood. In addition, the roles of satisfaction, loyalty and benefits should also be explored in the next study.

Secondly, the sample of this study was focused on college student consumers who are more willing to spend on new and fashionable technology. However, they do not have a strong purchasing power, because their financial sources almost exclusively come from their families. Therefore, data used in this paper could not represent consumers' perception as a whole and it may cause some unexpected biases. Furthermore, asking Taiwanese consumers' perception about Taiwanese company (HTC Company) in term of global brand issues made them 
confused because basically to Taiwanese, the HTC might seem as a local brand. Thus, future research should expand beyond Taiwan to collect information outside the country and should also concentrate on consumers who have independently finance situation.

Finally, there are many tycoons in the mobile phone industry such as iPhone, HTC, Samsung, Sonny, etc. So, it is essential to look at differences among these huge industries in term of consumers' perception in future research.

\section{References}

Aaker, D. A. (1991). Managing Brand Equity: Capitalizing On The Value Of A Brand Name (pp. 102-120). The Free press.

Ajzen, I., \& Fishbein, M. (1980). Understanding Attitudes and Predicting Social Behavior. Englewood Cliffs, NJ: Prentice Hall.

Armstrong, G., \& Kotler, P. (2011). Marketing an introduction (10th ed.). Upper Saddle River, New Jersey, NJ: Pearson Prentice Hall.

Baumgartner, H., \& Homburg, C. (1996). Applications of Structural Equation Modeling In Marketing and Consumer Research: A Review. International Journal of Research in Marketing, 13(2), 139-161. http://dx.doi.org/10.1016/0167-8116(95)00038-0

Batra, R., Ramaswamy, V., Alden, D. L., Steenkamp, J.-B. E. M., \& Ramachander, S. (2000). Effects of Brand Local and Nonlocal Origin on Consumer Attitudes in Developing Countries. Journal of Consumer Psychology, 9(2), 83-95. http://dx.doi.org/10.1207/15327660051044178

Baron, R. M., \& Kenny, D. A. (1986). The Moderator-Mediator Variable Distinction in Social Psychological Research: Conceptual, Strategic and Statistical Considerations. Journal of Personality and Social Psychology, 51(6), 1173-1182. http://dx.doi.org/10.1037//0022-3514.51.6.1173

Bearden, W. O., \& Etzel, M. J. (1982). Reference group influence on product and brand purchase decisions. Journal of Consumer Research, 9(2), 183-194. http://dx.doi.org/10.1086/208911

Bentler, P. M. (1992). On The Fit of Models to Covariance and Methodology to the Bulletin. Psychological Bulletin, 112(3), 400-404. http://dx.doi.org/10.1037//0033-2909.112.3.400

Bhardwaj, V., Kumar, A., \& Kim, Y. (2010). Brand analyses of US global and local brands in India: the case of Levi's. Journal of Global Marketing, 23(1), 80-95. http://dx.doi.org/10.1080/08911760903442226

Brown, M. (2010). Welcome to the fifth annual Brand Top 100 Most Valuable Global Brands Ranking. Retrieved from http://c1547732.cdn.cloudfiles.rackspacecloud.com/BrandZ_Top100_2010.pdf

Brown, T. A. (2006). Confirmatory Factor Analysis for Applied Research. New York: Guilford Press.

Chi, H. K., Yeh, H. R., \& Yang, Y. T. (2009). The Impact of Brand Awareness on Consumer Purchase Intention: The Mediating Effect of Perceived Quality and Brand Loyalty. The Journal of International Management Studies, 4(1), 135-144.

Chin, W. W., \& Todd, P. A. (1995). On the Use, Usefulness, and Ease of Use of Structural Equation Modeling In MIS Research: A Note of Caution. MIS Quarterly, 19(2), 237-246. http://dx.doi.org/10.2307/249690

DeCoster, J. (1998). Overview of Factor Analysis. Retrieved from http://www.stat-help.com/factor.pdf

Dou, W., Wang, G., \& Zhou, N. (2006). Generational and regional differences in media consumption patterns of Chinese generation $\mathrm{X}$ consumers. Journal of Advertising, 35(2), 101-110. http://dx.doi.org/10.1080/00913367.2006.10639230

Eckhardt, G. M. (2005). Local Branding in a Foreign Product Category in an Emerging Market. Journal of International Marketing, 13(4), 57-79. http://dx.doi.org/10.1509/jimk.2005.13.4.57

Fairchild, A. J., \& McQuillin, S. D. (2010). Evaluating mediation and moderation effects in school psychology: A presentation of methods and review of current practice. Journal of School Psychology, 8(1), 53-84. http://dx.doi.org/10.1016/j.jsp.2009.09.001

Fornell, C. R., \& Larcker, F. F. (1981). Structural Equation Models with Unobservable Variables and Measurement Error. Journal of Marketing Research, 18(1), 39-50. http://dx.doi.org/10.2307/3151312

Gielens, K., \& Steenkamp, J. B. E. M. (2007). Drivers of Consumer Acceptance of New Packaged Goods: An Investigation across Products and Countries. International Journal of Research in Marketing, 24(2), 97-111. 
http://dx.doi.org/10.1016/j.jiresmar.2006.12.003

Ger, G. (1999). Localizing in the Global Village: Local Firms Competing in Global Markets. California Management Review, 41(4), 64-83. http://dx.doi.org/10.2307/41166010

Ger, G., Belk, R. W., \& Lascu, D. N. (1993). The Development of Consumer Desire in Marketizing and Developing Economies: The Cases of Romania and Turkey. Advances in Consumer Research, 20(1), 102-107.

Hair, J. E., Anderson, R. E., Tatham, R. L., \& Black, W. C. (1998). Multivariate Data Analysis (5th ed.). Upper Saddle River, NJ: Prentice-Hall.

Han, C. M. (1990). Testing the role of country image in consumer choice behavior. European Journal of Marketing, 26(6), 24-40. http://dx.doi.org/10.1108/EUM0000000000609

Jae-On, K., \& Mueller, C. W. (1978). Factor Analysis: Statistical Methods and Practical Issues. SAGE Publications, Inc.

Johansson, J. K., \& Ilkka, A. R. (2004). Consider Implications of Local Brands in a Global Arena. Marketing News, 38(6), 46-48.

Kapferer, J. N. (1997). Strategic brand management: New approaches to creating and evaluating brand equity. Dover, N.H.: Kogan Page.

Keller, K. L. (1997). Strategic brand management: Building, measuring and managing brand equity. Upper Saddle River, NJ: Prentice-Hall.

Kerlinger, F. N., \& Lee, H. B. (2000). Foundations of Behavioral Research (4th ed.). Holt, NY: Harcourt College Publishers.

Kinra, N. (2006). The Effect of Country-Of-Origin on Foreign Brand Names in the Indian Market. Marketing Intelligence \& Planning, 24(1), 15-30. http://dx.doi.org/10.1108/02634500610641534

Kotler, P. (2003). Marketing Management (11th ed.). India: Pearson education.

Lee, H. J., Kumar, A., \& Kim, Y. K. (2010). Indian Consumers' Brand Equity toward a US and Local Apparel Brand. Journal of Fashion Marketing and Management, 14(3), 469-485. http://dx.doi.org/10.1108/13612021011061898

Lukose, R. (2005). Consuming globalization: Youth and gender in Kerala, India. Journal of Social History, 38(4), 915-935. http://dx.doi.org/10.1353/jsh.2005.0068

MacKinnon, D. P., Fairchild, A. J., \& Fritz, M. S. (2007). Mediation Analysis. Annual Review of Psychology, 58(1), 593-614. http://dx.doi.org/10.1146/annurev.psych.58.110405.085542

Malek, M. (2012). International Tourists Satisfaction: Case of Jordan. International Business Research, 5(9), 210-216. http://dx.doi.org/10.5539/ibr.v5n9p210

Milberg, S. J., \& Sinn, F. (2008). Vulnerability of global brands to negative feedback effects. Journal of Business Research, 61(6), 684-690. http://dx.doi.org/10.1016/j.jbusres.2007.06.045

Mitra, D., \& Golder, P. N. (2006). How Does Objective Quality Affect Perceived Quality? Short-Term Effects, Long-Term Effects, and Asymmetries. Marketing Science, 25(3), 230-247. http://dx.doi.org/10.1287/mksc.1050.0175

Ratner, B. (2011). Statistical and Machine-Learning Data Mining: Techniques for Better Predictive Modeling and Analysis of Big Data (2nd ed.). CRC Press.

Sekaran, U. (2000). Research Methods for Business: A Skills Building Approach (3rd ed.). New York: John Wiley \& Sons.

Schuiling, I., \& Kapferer, J. N. (2004). Real Differences between Local and International Brands: Strategic Implications for International Marketers. Journal of International Marketing, 12(4), 97-112. http://dx.doi.org/10.1509/jimk.12.4.97.53217

Steenkamp, J.-B. E. M., Batra, R., \& Alden, D. L. (2003). How Perceived Globalness Creates Brand Value. Journal of International Business Studies, 34(1), 53-65. http://dx.doi.org/10.1057/palgrave.jibs.8400002

Shocker, A. D., Srivastava, R., \& Ruekert, R. W. (1994). Challenges and Opportunities Facing Brand Management: An Introduction to the Special Issue. Journal of Marketing Research, 31(2), 149-158. http://dx.doi.org/10.2307/3152190 
Strizhakova, Y., Coulter, R. A., \& Price, L. L. (2011). Branding in a Global Marketplace: The Mediating Effects of Quality and Self-Identity Brand Signals. International Journal of Research in Marketing, 28(4), 343-351. http://dx.doi.org/10.1016/j.jiresmar.2011.05.007

Tavakoli, A. S., Jackson, K., \& Moneyham, L. (2009). Examining Mediator and Moderator Effect Using Rural Women HIV Study. SAS Global Forum, 2009.

Vigneron, F., \& Johnson, L. W. (1999). A Review and a Conceptual Framework of Prestige-Seeking Consumer Behavior. Academy of Marketing Science Review, 99(1), 245-257.

Field, A. P. (2005). Discovering statistics using SPSS (2nd ed.). London: Sage.

Wolfe, A. (1991). The Single European Market: National of Euro-Brands. International Journal of Advertising, 10(1), 49-58.

Yu, C., \& Dong, L. (2010). Global Brands and Local Attitudes: Examination from a Transitional Market. Global Brand Management Conference. Istanbul, Turkey Conference, June 20-22, 2010.

Zhou, L., \& Hui, M. K. (2007). Confidence in Brand Origin and Its Strategic Implications: Evidence from A Developing Market. ASAC 2007 Ottawa, Ontario.

Zhou, L., Teng, L., \& Poon, P. (2006). Susceptibility to Global Consumer Culture Influence: A Three-Dimensional Scale. Annual Conference of the Administrative Science Association of Canada (ASAC), Banff, Alberta, Canada.

\section{Copyrights}

Copyright for this article is retained by the author(s), with first publication rights granted to the journal.

This is an open-access article distributed under the terms and conditions of the Creative Commons Attribution license (http://creativecommons.org/licenses/by/3.0/). 